\title{
Image guided cryoablation of cancer with intra- tumoral injection of anti-CTLA-4 and PD-1 immune check-point inhibitors
}

Mark A Rosenberg ${ }^{1}$, Jason Williams ${ }^{2^{*}}$

From 30th Annual Meeting and Associated Programs of the Society for Immunotherapy of Cancer (SITC 2015) National Harbor, MD, USA. 4-8 November 2015

\section{Background}

Image guided cryoablation of cancer destroys tumor tissue and can activate tumor-specific $\mathrm{T}$ cells by increasing the presentation of tumor antigens and causing the release of "Danger signals" to stimulate the immune system. However, the development of a systemic anti-cancer

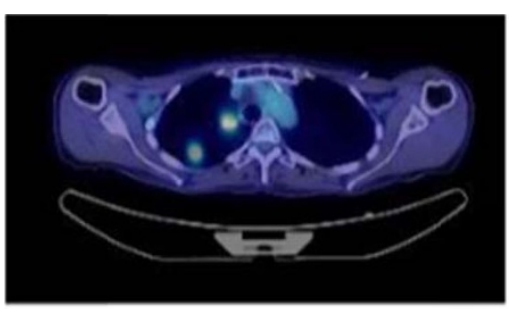

Image above demonstrates FDG PET/CT with abnormal uptake in two right upper lobe nodules.

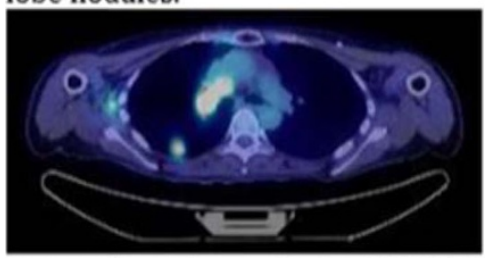

Image above demonstrates FDG PET/CT with abnormal uptake in right supra-hilar lymph nodes, right upper lobe nodule and right axillary lymph node.

Figure 1

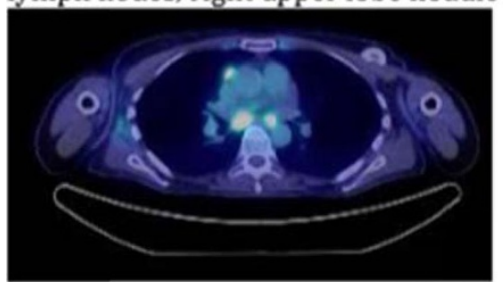

Image above demonstrates FDG PET/CT with abnormal uptake in bilateral infrahilar and right peri-aortic lymph nodes.

${ }^{2}$ Cancer Immune Biologics, Dunwoody, GA, USA

Full list of author information is available at the end of the article

(c) 2015 Rosenberg and Williams This is an Open Access article distributed under the terms of the Creative Commons Attribution 
immune response may be restrained by immune checkpoint inhibitors. In recent years, the U.S. Food and Drug Administration-approved antibody drug ipilumimab, nivolumab and pembrolizumab as inhibitors of CTLA-4

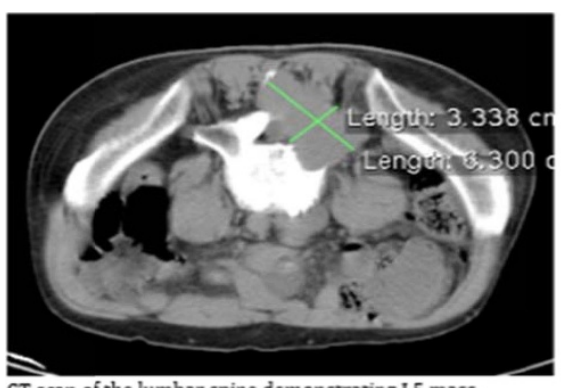

CT scan of the lumbar spine demonstrating L5 mass.

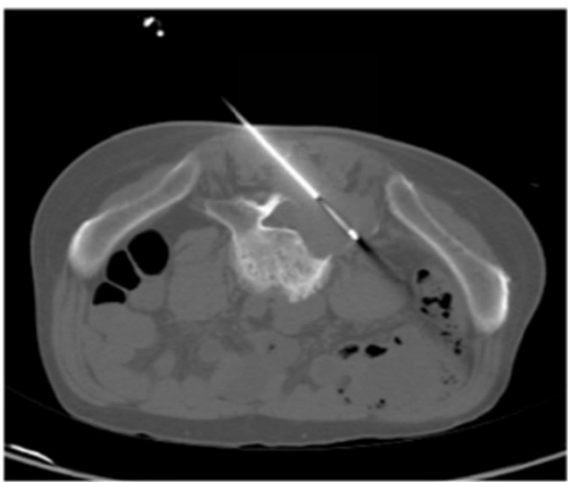

CT scan during ablation procedure demonstrating Cryoablation of L5 mass.

Figure 6

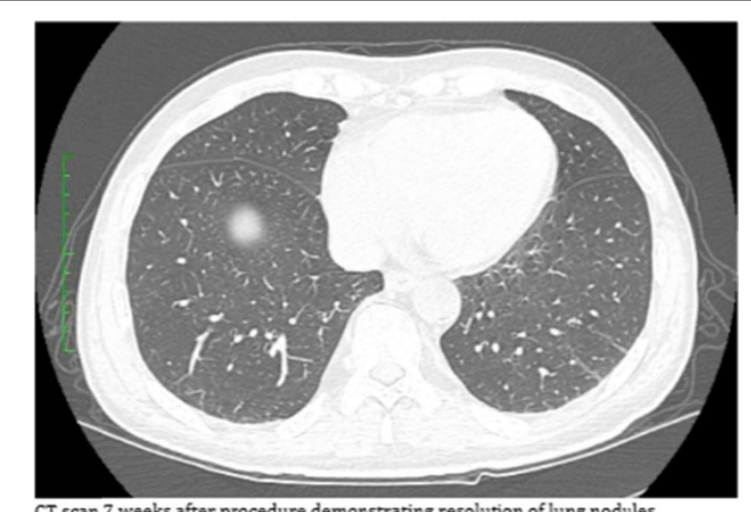

CT scan 7 weeks after procedure demonstrating resolution of lung nodules.

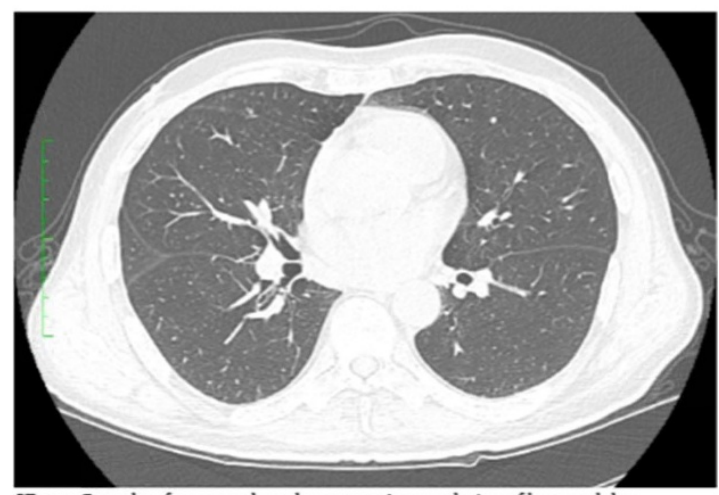

CT scan 7 weeks after procedure demonstrating resolution of lung nodules.

Figure 7 

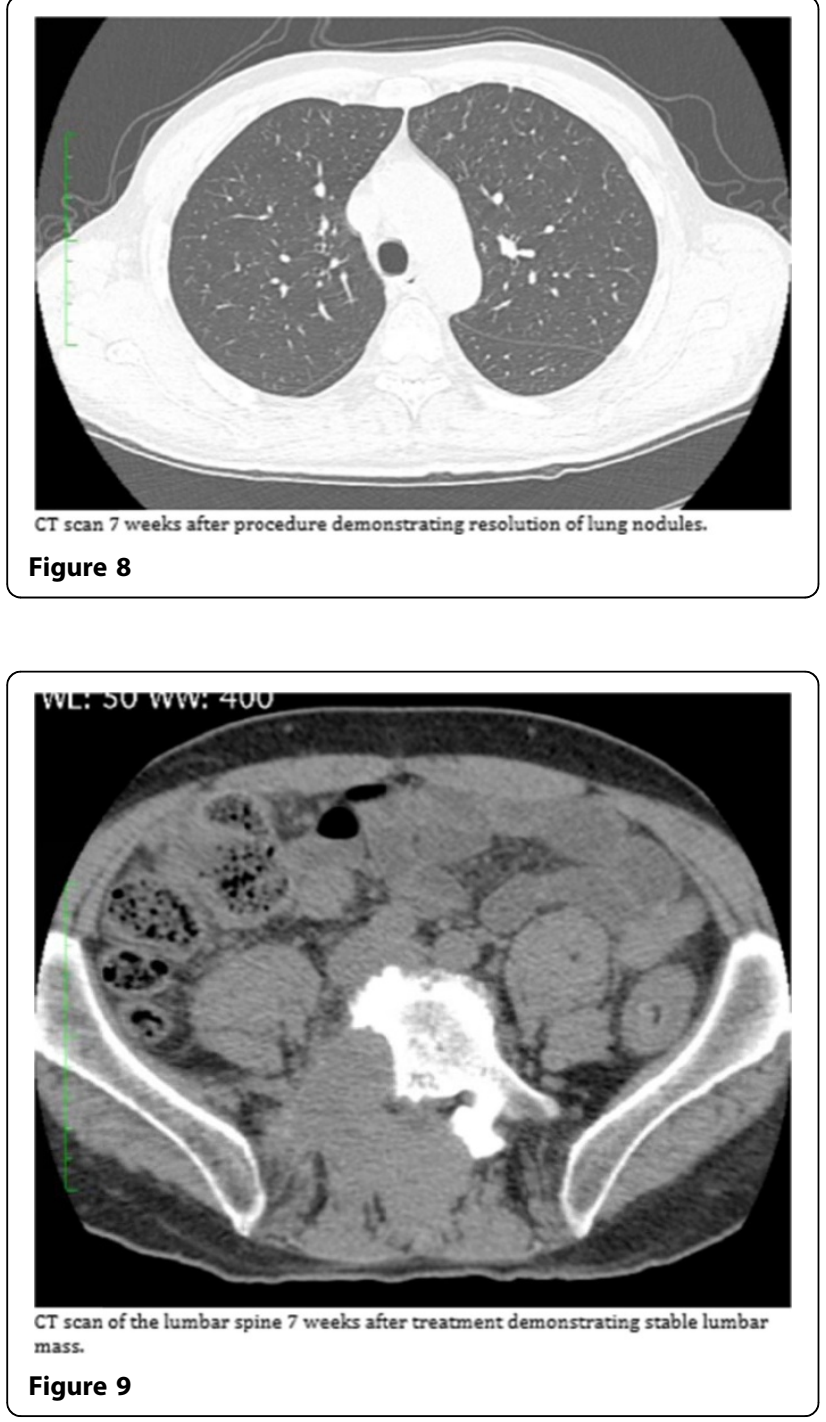

and PD-1. By blocking these immune check-point receptors, these antibodies can promote tumor rejection, but their full application has yet to be fully determined.

\section{Methods}

In our human case studies, we offer a proof-of-concept in multiple tumor types that intra-tumoral CTLA-4 and PD-1 blockade combined with cryoablation of a primary tumor can cause regression of secondary tumors at a distant site.

\section{Results}

From past clinical experience, we know that secondary tumors are unlikely to be affected by cryoablation alone, the combination treatment was sufficient to cause complete cancer regression and tumor rejection. Cryoablation is currently used to treat a targeted tumor, our results suggest that combination therapy with CTLA-4 and PD-1 blockade, by direct injection into the ablated tumor, will enhance anti-tumor immunity and rejection of tumor metastases.

\section{Authors' details}

${ }^{1}$ Cancer Immune Biologics, Boca Raton, FL, USA. ${ }^{2}$ Cancer Immune Biologics, Dunwoody, GA, USA.

Published: 4 November 2015

doi:10.1186/2051-1426-3-S2-P142

Cite this article as: Rosenberg and Williams: Image guided cryoablation of cancer with intra-tumoral injection of anti-CTLA-4 and PD-1 immune check-point inhibitors. Journal for ImmunoTherapy of Cancer 2015 3(Suppl 2):P142.

\section{Submit your next manuscript to BioMed Central} and take full advantage of:

- Convenient online submission

- Thorough peer review

- No space constraints or color figure charges

- Immediate publication on acceptance

- Inclusion in PubMed, CAS, Scopus and Google Scholar

- Research which is freely available for redistribution 